\title{
S100A2 induces the growth of Calu- 6 Lung Cancer Cells via apoptosis inhibition, invasion enhancement and promoting cell division
}

\section{Yiqian Liang}

xi'an jiaotong university

Ting Wang ( $\nabla$ hdwt.ok@163.com )

xi'an No.4 hospital

Bianling Yin

xi'an No.4 hospital

Asmitananda Thakur

Birat Medical College

Research article

Keywords: S100A2, Calu-6, apoptosis, invasion, cell cycle

Posted Date: March 31st, 2020

DOI: https://doi.org/10.21203/rs.3.rs-19436/v1

License: (c) (i) This work is licensed under a Creative Commons Attribution 4.0 International License.

Read Full License 


\section{Abstract}

\section{Background}

S100 calcium binding protein A2 (S100A2) has been confirmed to have an abnormal expression in lung cancer and is associated with a better disease-free internal of lung cancer patients. Our previous studies on S100A2 in lung cancer concentrated on the clinical roles of this protein in lung cancer, finding that S100A2 increasingly expressed in the sera, tissues and plural effusion of lung cancer patients. This study emphasizes its value in the lung cancer cell line.

\section{Methods}

We constructed a S100A2 expression lentivirus vector, then transfected it and blank vector into the Calu- 6 lung cancer cell line respectively. After the successful transfection, (which was confirmed by RT-PCR and Western-blot), we used MTT, transwell and flow cytometric analysis to compare the differences in cell proliferation, cell migration, cell invasion, cell apoptosis and cell cycle among the three groups (Calu-6, Calu/neo, Calu-6/S100A2).

Results

Calu-6 lung cancer cells showed a shift from $\mathrm{G} 1$ to $\mathrm{S}$ phase after being transfected with S100A2, compared with the control groups. Additionally, Calu-6/S1000A2 cells had enhanced abilities of invasion and down-abilities of apoptosis in contrast with the blank groups $(P<0.05)$. However, there were no significant difference among these three group in the cell behaviors of migration and proliferation $(P>0.05)$.

\section{Conclusion}

Our results firstly indicate that S100A2 has a positive influence on the biological characteristics of Calu-6 lung cancer cell line, including cell division, invasion and apoptosis inhibition. It may play a significant role in the genesis and progression of lung cancer.

\section{Introduction}

Lung cancer has become the leading cause of cancer-related mortality, with approximately $1,761,000$ deaths all over the world in 2018. It experienced a relatively high incidence in both genders, accounting for $14.5 \%$ and $8.4 \%$ of all new cancer cases in males and females respectively [1]. Because of an increased prevalence of risk factors, such as smoking, air pollution, population aging, the occurrence of this carcinoma will increase persistently. Due to lack of typical symptoms and signs, as well as being radiologically occult, lung cancer patients are generally diagnosed at an advanced stage, having little opportunity for surgical resection [2]. However, because of invasiveness, histological confirmation after biopsy, which severs as the diagnostic standard, is not readily accepted by suspected patients unless they are convinced of the high probability of lung cancer [3]. Molecular biomarkers are widely applied in 
clinical work to assist with the early detection of lung cancer and screen malignant lung nodules. True positive or -negative results positively influence the clinical management in a manner of favorable outcomes for patients [4,5]. In last few years, there is an increasing interest about the use of biomarkers in lung cancer, including classical ones such as CEA, CYFRA21-1 and new ones such as PD-L1 [6, 7].

S100 protein family is the largest subfamily of calcium-binding proteins with EF-hand type, containing a total of 25 known human members each coded by a separate gene. Among these genes, at least 14 cluster to the epidermal differentiation complex (EDC) on chromosome

$1 \mathrm{q} 21$, where is prone to chromosomal rearrangements $[8,9]$. Some members in this group are found to be multifunctional proteins that are expressed differently in a variety of cell types and get involved in the regulation of inflammatory response, cellular activities like cell differentiation [10,11]. Through binding target proteins or genes (e.g., p53), a number of S100 members could also fulfill kinds of intra- or extracellular functions [12]. Expression of several S100 proteins such as S100A4, S100B, and S100A6 are abnormal in some cancers, including lung carcinoma $[13,14]$. S100A2 plays a specific role in S100 protein family but there are conflicting results about its function in cancer. In 1992, Lee et al initially reported that S100A2 was down regulated in breast cancer, may act as a tumor suppressor [15]. However, many researchers proposed different views afterwards, suggesting that S100A2 could stimulate cell invasion, poor differentiation and metastasis in some cancers like gastric neoplasia [16]. Similarly, contrary study findings also exist in lung cancer, questioning the function of S100A2 [17, 18]. Our previous researches confirmed that S100A2 expressed at a high level in the sera, tissues and pleural effusion of NSCLC patients [19]. In this study, we evaluated S100A2 gene effects in lung cancer cell line through infecting Calu- 6 lung cancer cells by lentivirus vector.

\section{Materials And Methods}

Cell culture

The lung cancer cell line Calu- 6 was bought from Chinese Academy of Sciences. Cells were preserved at $37^{\circ} \mathrm{C}$ and $5 \% \mathrm{CO}_{2}$, maintained and expanded in growth medium containing high glucose DMEM (Gibco, USA) combined with $15 \%$ heated-inactivated fetal bovine serum (FBS, Zhengbo, Beijing, China) and $100 \mathrm{U} / \mathrm{ml}$ streptomycin/penicillin (Gibco, USA) for one to two weeks.

Construction of pLVX-AcGFP1-N1-S100A2

PLVX-AcGFP1-N1-S100A2 was generated by PCR method using pcDNA-S100A2. The primers were designed as follows: the forward primer was 5'-CCCAAGCTTACCATGTGCAGTTCTCTGGAGCAG-3' and the reverse primer was 5'-GACGGGTCTGGCTGGGCCTTAAGGC-3'. DNA sequencing was then applied to verify the Orientation and the insert sequence.

Virus production and concentration 
Plvx-acgfp1-n1-S100A2, pspax2 and pmd2. G were co-transfected into 293T cells with a ratio of 2:1:1. The fluorescence expression was observed under the microscope after 72 hours and the supernatant was collected prior to be filtered through a $0.45 \mu \mathrm{m}$ PVDF filter (Millipore). Thirty-fold concentrated stock was obtained by ultracentrifugation $\left(50000 \mathrm{~g}, 150 \mathrm{~min}, 4^{\circ} \mathrm{C}\right)$. The pellets were resuspended in PBS and stored at $-80^{\circ} \mathrm{C}$.

\section{Cells infection}

Those Calu- 6 cells grown in logarithmic phase were collected, trypsinized to a density of $3 * 10^{5} / \mathrm{ml}$ and planted in 6-well plate (JET BIOFIL, Guangzhou, China), then cultured in incubator. S100A2 overexpressed lentivirus $(\mathrm{MOI}=10)$ was added when cell confluence reached $80-90 \%$. Meanwhile, we transfected Calu- 6 cells with blank vector control lentivirus $(\mathrm{MOI}=10)$ as one control group. It is also notable that another control group was empty Calu-6 cells with no vector. We designated all these three groups as Calu-6/S100A2, Calu-6/neo and Calu-6. The infection efficiency was observed by fluorescence microscopy after 48 hours, and the infected S100A2 gene was confirmed by subsequent experiments including QPCR and WB.

RNA extraction and QPCR

We applied TRIzol reagent (Invitrogen, USA) for cell lysis, then collected the centrifugal supernatant. To get purified RNA, chloroform, 2-propanol and 75\% ethanol were successively added into the supernatant to separate RNA from DNA and protein. After the extraction, we used Nanodrop 2000 (Thermo, USA) to detect the concentration and purity of RNA. RevertAid First Strand cDNA Synthesis Kit (Thermo, USA) helped us achieve the process of reverse transcription, and cDNA was synthesized from 2 ml RNA by RevertAid $^{\text {TM }}$ M-MuLV, 10 mM dNTPs, $1 \mu$ l oligo (dT) 18 primers, reverse transcriptase, and $1 \mu$ l Ribolock ${ }^{\text {TM }}$ ribonuclease inhibitor. All operations were strictly operated according to the kit instructions. The specific procedures and conditions in PCR were incubation $\left(95^{\circ} \mathrm{C}, 5 \mathrm{~min}\right)$, denaturation $\left(94^{\circ} \mathrm{C}, 30 \mathrm{~s}\right.$ for 44 circles), annealing $\left(55^{\circ} \mathrm{C}, 30 \mathrm{~s}\right)$, extension $\left(72^{\circ} \mathrm{C}, 30 \mathrm{~s}\right)$. In addition to that, the information about primers used in PCR was as follows: S1002 forward primer (5-GCCAAGAGGGCGACAAGTT-3) and S1002 reversed primer (5-AGGAAAACAGCATACTCCTGGA-3); glyceraldehyde-3-phosphate dehydrogenase (GAPDH, an endogenous control) forward primer (5-GGAGCGAGATCCCTCCAAAAT-3) and GAPDH reversed primer (5GGCTGTTGTCATACTTCTCATGG-3).

Western Blot

The western bolt experiment was used to determine the protein expression of Calu-6/S100A2. Forty-eight hours after transfection, we collected the cells and used a Total Protein Extraction Kit for further acquisition of cell lysate. Then, we added loading sample buffer to the lysate after clarifying it with centrifugation (at 14,000 rpm, $10 \mathrm{~min}$ ), heated for $5 \mathrm{~min}$ at $95^{\circ} \mathrm{C}$, and separated by $10 \%$ sodium dodecyl sulfate-polyacrylamide before transferring it to a nitrocellulose membrane. Nitrocellulose filters were blocked by $5 \%$ non-fat milk, and then incubated with primary antibody against S100A2 (PAC009Hu01, USCN Life Sciences Inc., Wuhan, China, 1/500 dilution) at $4^{\circ} \mathrm{C}$ overnight. At the same time, the mouse 
GAPDH antibody was set as an endogenous control. Subsequently, we rinsed the membrane, added the secondary antibodies (SAA544Rb59, USCN Life Sciences Inc., Wuhan, China, 1/5000 dilution) with horseradish peroxidase-labeled polymer to it, re-rinse, and then used enhanced chemiluminescence to observe the imaging.

\section{MTT proliferation growth curve}

The MTT assay was used to analyze cell proliferation. Firstly, the three group cells (Calu-6, Calu-6/neo, Calu-6/S100A2) at logarithmic phase were collected, centrifuged to cell suspension, and adjusted to a concentration of $5-10 \times 10^{4} / \mathrm{ml}$. Then, $100 \mu \mathrm{l}$ cell suspension was seeded into every well of 96 -well plates. After being cultured in incubator, we measured the absorbance at 12, 24, 48,72 and 96 hours respectively. Next, a total of $10 \mu \mathrm{l}$ MTT stock solutions was added to every well, then incubated at $37^{\circ} \mathrm{C}$ for 4 hours before adding Formazan solution. Finally, the absorbance of each well was detected by ELISA at $490 \mathrm{~nm}$.

Transwell migration and invasion assay

To examine cell migration in vitro, we applied the transwell assay. Logarithmic cells were taken, digested by $0.25 \%$ trypsin, centrifuged at $800 \mathrm{rpm}$ for $5 \mathrm{~min}$, and adjusted to a density of $1 * 10^{6} / \mathrm{ml}$. We placed the Calu-6, Calu-6/neo, Calu-6/S100A2 cells (each $100 \mu \mathrm{l}$ ) in the upper chamber of six-well transwell plates, which was matrigel-uncoated and consisted of $8.0 \mu \mathrm{m}$ pore size filters, and added $600 \mu \mathrm{l}$ DMEM medium (containing $30 \% \mathrm{FBS}$ ) to the lower chamber. The plates then were incubated under the condition of $37^{\circ} \mathrm{C}$ and $5 \% \mathrm{CO}_{2}$ for 48 hours. After the incubation, we removed the upper cells with cotton-tipped swabs, fixed the filters in ethanol and stained it with hematoxylin. Five separate fields of cells on the underside were observed and took photography under the 100 -fold optical microscope. The procedures of transwell assay for cell invasion detection were similar as above processes. The slight difference was that six-well transwell plates used was matrigel-coated.

\section{Flow cytometry}

We applied flow cytometry to investigate S100A2's function in cell apoptosis and cell cycle. Cell suspension was prepared by centrifugation of logarithmic phase cells, and the count was adjusted to $3^{\star} 10^{5} / \mathrm{mL}$. Approximately $2000 \mu \mathrm{l}$ cell suspension was placed into 6 -well plate, incubated for 48 hours, and then washed twice by cool PBS, centrifuged at $1000 \mathrm{rpm}$ for 5 minutes at $4^{\circ} \mathrm{C}$. Next, we collected a number of $1-5^{\star} 10^{5}$ cells, mixed them with $100 \mu$ l binding buffer after absorbing PBS. $10 \mu$ l Annexin VFITC and $5 \mu$ l of PI staining solution were added afterwards before the incubation at room temperature for $15 \mathrm{~min}$ in the dark. At the last step, the mixture was added to $400 \mu$ l binding buffer and analyzed by FACSCalibur system in one hour. As for the flow cytometry procedures for cell cycle, after the centrifugation, cells were fixed in $75 \%$ ethanol for $1 \mathrm{~h}$, washed by PBS, treated with $100 \mathrm{~L}$ RNaseA solution, and then resuspended before being bathed in water at $37^{\circ} \mathrm{C}$ for 30 minutes. The cell precipitation was incubated in the dark at $4^{\circ} \mathrm{C}$ for 30 minutes in the presence of $400 \mu \mathrm{l} \mathrm{PI}$ dyeing solution, 
and the mixture was then analyzed by flow cytometry at an excitation wavelength of $488 \mathrm{~nm}$. We used Cell Quest and MidFit softwares to determine the cell cycles, which mainly contains three major phases G1, S, G2.

Statistical analysis

GraphPad Prism 7.0 and the SPSS 22.0 statistical package were performed to make bar graphs and analyze data. A two-tailed $\mathrm{P}<0.05$ was considered to indicate statistical significance.

\section{Results}

S100A2's expression at mRNA and protein levels after transfection

According to whether being transfected by S100A2 expression lentivirus vector or not, lung cancer Cells were divided into three groups, which specifically referred to Calu- 6 cells, Calu-6/blank vector and Calu6/S100A2. After the transfection, we used fluorescence microscope, RT-PCR method and western blot analysis to illustrate the infection efficiency. Results show that, as listed in Fig. 1, compared with the control groups, S100A2 highly expressed in the Calu-6/S100A2 cells, experiencing an upward trend of mRNA expression (Fig. 1a) and protein expression (Fig. 1b). Meanwhile, the Calu- 6 cells were observed having a weak green fluorescence, reminding us high transfection efficiency, as showed in Fig. 1c.

S100A2 had no influence on cells' proliferation and migration

The effects of S100A2 on cells' behaviors, including proliferation and migration, were examined by MTT method and transwell assay. Figure 2 and Fig. 3 gave us information that the abilities of cell proliferation and migration had no difference among three groups, with both $P>0.05$.

S100A2 accelerated the invasion of Calu- 6 cells

Transwell assay showed that S100A2 may play a positive role in cell invasion. As showed by data in Fig. 4 , with a mean cell count of $495.3 \pm 10.68$, the group of Calu-6/S100A2 had a stronger invasive ability than Calu- 6 cells $(441.7 \pm 4.91)$ and Calu-6/neo cells $(441.0 \pm 7.94)$. The difference was statistically significant.

S100A2 inhibited apoptosis and enhanced the cell cycle of Calu- 6 cells

Flow cytometry was performed to detect the functions of S100A2 on lung cancer cell line's behaviors, such as apoptosis and changes in cell cycle. As demonstrated in Fig. 5, the mean proportion of apoptotic cells in the Calu-6/S100A2 group accounted for $(6.32 \pm 0.04) \%$, which was significantly lower than its counterpart in Calu- 6 cells and Calu- $6 /$ neo cells $-(8.86 \pm 0.61) \%$ and $(8.01 \pm 0.07) \%$ respectively.

Compared with the control groups, as showed in Fig. 6, Calu-6/S100A2 cells had a relatively lower percentage in $\mathrm{G} 1$ phase and higher percentage of S phase, indicating that S100A2 promoted the cell cycle of Calu- 6 cells and accelerated the transition from $\mathrm{G} 1$ to $S$ phase in Calu- 6 cells. More concretely, the 
proportions of three groups in G1 phase were $(70.98 \pm 0.74) \%$ (Calu-6), $(66.97 \pm 0.18) \%$ (Calu-6/neo) and $(52.16 \pm 0.78) \%$ (Calu-6/S100A2); while, in S phase, they were $(28.58 \pm 0.70) \%$, $(34.18 \pm 1.81) \%$ and $(47.69 \pm 0.84) \%$ respectively. The differences were dramatically significant, with $\mathrm{P}<0.01$.

All the results were representative of triplicate experiments and were displayed as mean \pm SD.

\section{Discussion}

In this study, we constructed a S100A2 expression lentivirus vector, transfected it into the Calu- 6 cells, and further investigated the role S100A2 played in this lung cancer cell line. Through the comparison of cells' behaviors among three groups (Calu-6, Calu-6/neo, Calu-6/S100A2), we consolidated the association of S100A2 overexpression with enhanced cell invasion, cell cycle and decreased apoptosis, finding that S100A2 may promote the genesis and progress of lung cancer.

In recent years, a certain number of members in S100 protein family emerged as valuable diagnostic and prognostic biomarkers in several types of cancers and draw increasing attention from researchers. Through binding $\mathrm{Ca}^{2+}$ and activating $\mathrm{Ca}^{2+}{ }_{-}$-mediated signaling pathways, these proteins participate in many cell activities, such as cell cycle progression, differentiation, etc [20]. As an important and unique member in this family, S100A2 has also been found to have an altered expression in different type of tumors $[21,22]$. Since the gene of this 99 -amino acid protein is located on chromosome 1q21, which is a frequently rearranged area, S100A2 has been reported to relate with tumorigenesis [23]. The uniqueness of S100A2 depends on its distinct effects in different cancers and its various expressions in the same carcinoma. Initially, S100A2 (originally called clone 19), was found by Lee et al. to have a preferential expression in normal mammary epithelial cells but not in breast tumor cells, and its expression was reactivated in mammary tumor cells after the exposure of an inhibitor of DNA methylation. Researcher hence believed that S100A2, unlike most members of the $\mathrm{S} 100$ protein family, might work as a tumor suppressor in cancer [15]. In next following decades, there were more and more studies concerning S100A2 and cancer and conflicting finding were constantly emerging. For instance, in gastric cancer, researchers confirmed that S100A2 had a deceased expression, and this down-regulated level was related to poor differentiation, advanced invasion and distant metastasis [24]. Nevertheless, the study aiming to examine the expression of S100A2 in the multistep cholangiocarcinogenesis clarified that this protein increased in biliary intraepithelial neoplasia as well as invasive adenocarcinoma of perihilar cholangiocarcinoma, the expression of which was same with other S100 proteins like S100A4, S100A6, and S100P [25].

There were also a number of inconsistent findings with regard to the exact role S100A2 played in lung cancer. The earliest study on the relationship between S100A2 and lung cancer was in 2001, researchers used a cDNA array to screen for genes that were expressed differently in normal human bronchial epithelial (NHBE) cells and a tumorigenic cell line (1170-I), identifying the S100A2 gene as being downregulated in the 1170-I cells. Furthermore, compared with high expression in NHBE cells, S100A2 mRNA and protein levels were even undetectable in certain non-small cell lung cancer cell line [26]. Therefore, 
investigator examined its potential role as a tumor suppressor in lung carcinogenesis. However, after one year, Heighway et al. used a panel of cDNA microarrays to carry out a dual-channel analysis of gene expression, their microarray, cmRT-PCR, Western and immunohistochemistry data all indicated that S100A2 was strongly expressed in non-small cell lung cancer (NSCLC) [27]. Their conclusion was supported by many subsequent studies, some of which even found that this $\mathrm{S} 100$ protein was linked with lymphoma development and poor prognosis [28-30]. Studies focusing on the exact mechanism and signal conduction pathway found that $\$ 100 \mathrm{~A} 2$ got involved in TGF- $\beta$-mediated cell migration and invasion through p53-protein- and TGF- $\beta$-induced MAPK signaling. Meanwhile, this kind of induction could be manifested by interacting with Smad3, which was strengthened in the presence of high calcium and TGF- $\beta$. On the other hand, loss of S100A2 weakened TGF- $\beta /$ Smad 3 target genes' transcription, thus attenuating tumor promotion [31]. Based on previous investigations, some scholars proposed the viewpoint that the expression of S100A2 is particularly dominant at the early stage of NSCLC then decreases in the invasive carcinomas, named it as S100A2's dual role in NSCLC. Therefore, we propose the hypothesis that S100A2 is regulated by two opposite factors in NSCLC, may be mainly modulated by different mediator at various stages. This may explain why S100A2 in our experiment having positive influence on cell invasion while showing no obvious effects on cell migration. However, our results seems having some inconsistencies with previous study [32]. More in-depth researches hereafter are needed to clarify the exact mechanism of S100A2 in NSCLC.

Taken together, our cellular-level experiments identify S100A2 as an oncogenesis participant in manners of apoptosis inhibition, invasion enhancement as well as promoting cell division. In future, it may serve as a diagnostic marker for this malignant tumor. Our study, up to now, is a relatively comprehensive experimental confirmation about S100A2's effects on lung cell behaviors.

\section{Declarations}

\section{Acknowledgments}

This study was supported by Key Research and Development Program of Shaanxi Province (Grant No. 2018SF-219), Xi'an Municipal Science and Technology Project (Grant No. 201805093YX1SF27(4)) and the Fundamental Research Funds for the Central Universities in Xi'an Jiaotong University (No. xzy012019109).

\section{Conflict of Interest}

The authors declare that they have no competing interests.

\section{References}

1. Bray F, Ferlay J, Soerjomataram I, Siegel RL, Torre LA, Jemal A: Global cancer statistics 2018: GLOBOCAN estimates of incidence and mortality worldwide for 36 cancers in 185 countries. $C A$ : a cancer journal for clinicians 2018, 68(6):394-424. 
2. Claiborne PM, Fowler CS, Vaporciyan AA: Follow-up of patients with resected thoracic malignancies. Thoracic surgery clinics 2012, 22(1):123-131, viii.

3. Travis WD, Rekhtman N: Pathological diagnosis and classification of lung cancer in small biopsies and cytology: strategic management of tissue for molecular testing. Seminars in respiratory and critical care medicine 2011, 32(1):22-31.

4. Zhang YL, Zhang ZL, Zhu XB, Xu L, Lu P, Xu M, Liu WJ, Zhang XY, Yao HM, Ye XW: Low plasma miR25 expression is a favorite prognosis factor in non-small cell lung cancer. European review for medical and pharmacological sciences 2019, 23(12):5251-5259.

5. Mazzone PJ, Sears CR, Arenberg DA, Gaga M, Gould MK, Massion PP, Nair VS, Powell CA, Silvestri GA, Vachani A et al: Evaluating Molecular Biomarkers for the Early Detection of Lung Cancer: When Is a Biomarker Ready for Clinical Use? An Official American Thoracic Society Policy Statement. American journal of respiratory and critical care medicine 2017, 196(7):e15-e29.

6. Aguiar PN, Jr., De Mello RA, Hall P, Tadokoro H, Lima Lopes G: PD-L1 expression as a predictive biomarker in advanced non-small-cell lung cancer: updated survival data. Immunotherapy 2017, 9(6):499-506.

7. Okamura K, Takayama K, Izumi M, Harada T, Furuyama K, Nakanishi Y: Diagnostic value of CEA and CYFRA 21-1 tumor markers in primary lung cancer. Lung Cancer 2013, 80(1):45-49.

8. Marenholz I, Heizmann CW, Fritz G: S100 proteins in mouse and man: from evolution to function and pathology (including an update of the nomenclature). Biochemical \& Biophysical Research Communications 2004, 322(4):1111-1122.

9. Schafer BW, Wicki R, Engelkamp D, Mattei MG, Heizmann CW: Isolation of a YAC clone covering a cluster of nine S100 genes on human chromosome 1q21: rationale for a new nomenclature of the S100 calcium-binding protein family. Genomics 1995, 25(3):638-643.

10. Nacken W, Roth J, Sorg C, Kerkhoff C: S100A9/S100A8: Myeloid representatives of the S100 protein family as prominent players in innate immunity. Microsc Res Tech 2003, 60(6):569-580.

11. Donato R: Intracellular and extracellular roles of S100 proteins. Microsc Res Tech 2003, 60(6):540551.

12. Wang T, Huo X, Chong Z, Khan H, Liu R, Wang T: A review of S100 protein family in lung cancer. Clinica chimica acta; international journal of clinical chemistry 2018, 476:54-59.

13. Lukanidin E, Sleeman JP: Building the niche: the role of the S100 proteins in metastatic growth. Seminars in cancer biology 2012, 22(3):216-225.

14. Mishra SK, Siddique HR, Saleem M: S100A4 calcium-binding protein is key player in tumor progression and metastasis: preclinical and clinical evidence. Cancer and Metastasis Reviews 2012, 31(1):163-172.

15. Lee SW, Tomasetto C, Swisshelm K, Keyomarsi K, Sager R: Down-Regulation of a Member of the S100 Gene Family in Mammary Carcinoma Cells and Reexpression by Azadeoxycytidine Treatment. Proceedings of the National Academy of Sciences of the United States of America 1992, 89(6):2504. 
16. Liu YF, Liu QQ, Wang X, Luo CH: Clinical significance of S100A2 expression in gastric cancer. Tumor Biology 2014, 35(4):3731-3741.

17. Feng G, Xu X, Youssef EM, Lotan R: Diminished expression of S100A2, a putative tumor suppressor, at early stage of human lung carcinogenesis. Cancer Res 2001, 61(21):7999-8004.

18. Wang T, Liang $Y$, Thakur A, Zhang S, Liu F, Khan H, Shi P, Wang N, Chen M, Ren H: Expression and clinicopathological significance of $\mathbf{S} 100$ calcium binding protein $\mathrm{A} 2$ in lung cancer patients of Chinese Han ethnicity. Clinica chimica acta; international journal of clinical chemistry 2017, 464:118122.

19. Wang T, Liang Y, Thakur A, Zhang S, Yang T, Chen T, Gao L, Chen M, Ren H: Diagnostic significance of S100A2 and S100A6 levels in sera of patients with non-small cell lung cancer. Tumour biology: the journal of the International Society for Oncodevelopmental Biology and Medicine 2016, 37(2):2299-2304.

20. Chen H, Xu C, Jin Q, Liu Z: S100 protein family in human cancer. American journal of cancer research 2014, 4(2):89-115.

21. Suzuki F, Oridate N, Homma A, Nakamaru Y, Nagahashi T, Yagi K, Yamaguchi S, Furuta Y, Fukuda S: S100A2 expression as a predictive marker for late cervical metastasis in stage I and II invasive squamous cell carcinoma of the oral cavity. Oncology Reports 2005, 14(6):1493-1498.

22. Liu D, Rudland PS, Sibson DR, Platt-Higgins A, Barraclough R: Expression of calcium-binding protein S100A2 in breast lesions. Br J Cancer 2000, 83(11):1473-1479.

23. Maelandsmo GM, Florenes VA, Mellingsaeter T, Hovig E, Kerbel RS, Fodstad O: Differential expression patterns of S100A2, S100A4 and S100A6 during progression of human malignant melanoma. International journal of cancer 1997, 74(4):464-469.

24. Luo J, Zhu Y, Yang G, Gong L, Wang B, Liu H: Loss of Reprimo and S100A2 expression in human gastric adenocarcinoma. Diagnostic cytopathology 2011, 39(10):752-757.

25. Sato Y, Harada K, Sasaki M, Nakanuma Y: Clinicopathological significance of S100 protein expression in cholangiocarcinoma. Journal of gastroenterology and hepatology 2013, 28(8):14221429.

26. Feng G, Xu X, Youssef EM, Lotan R: Diminished expression of S100A2, a putative tumor suppressor, at early stage of human lung carcinogenesis. Cancer Research 2001, 61(21):7999-8004.

27. Heighway J, Knapp T, Boyce L, Brennand S, Field JK, Betticher DC, Ratschiller D, Gugger M, Donovan $\mathrm{M}$, Lasek $\mathrm{A}$ et al: Expression profiling of primary non-small cell lung cancer for target identification. Oncogene 2002, 21(50):7749-7763.

28. Hsieh HL, Schafer BW, Sasaki N, Heizmann CW: Expression analysis of S100 proteins and RAGE in human tumors using tissue microarrays. Biochemical and biophysical research communications 2003, 307(2):375-381.

29. Diederichs S, Bulk E, Steffen B, Ji P, Tickenbrock L, Lang K, Zanker KS, Metzger R, Schneider PM, Gerke $V$ et al: $\mathbf{S 1 0 0}$ family members and trypsinogens are predictors of distant metastasis and survival in early-stage non-small cell lung cancer. Cancer Res 2004, 64(16):5564-5569. 
30. Smith SL, Gugger M, Hoban P, Ratschiller D, Watson SG, Field JK, Betticher DC, Heighway J: S100A2 is strongly expressed in airway basal cells, preneoplastic bronchial lesions and primary non-small cell lung carcinomas. Br J Cancer 2004, 91(8):1515-1524.

31. Naz S, Bashir M, Ranganathan P, Bodapati P, Santosh V, Kondaiah P: Protumorigenic actions of S100A2 involve regulation of PI3/Akt signaling and functional interaction with Smad3.

Carcinogenesis 2014, 35(1):14-23.

32. Bulk E, Sargin B, Krug U, Hascher A, Jun Y, Knop M, Kerkhoff C, Gerke V, Liersch R, Mesters RM et al: S100A2 induces metastasis in non-small cell lung cancer. Clinical cancer research : an official journal of the American Association for Cancer Research 2009, 15(1):22-29.

\section{Figures}

a

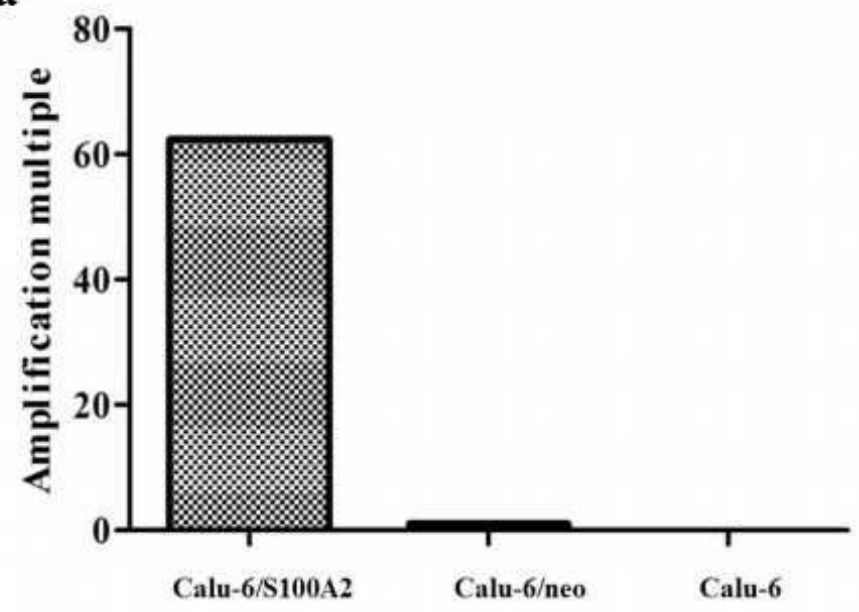

b

Calu-6 Calu-6/neo Calu-6/S100A2

S100A2

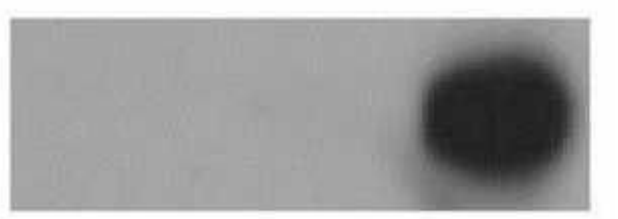

$42 \mathrm{Kd}$

GAPDH

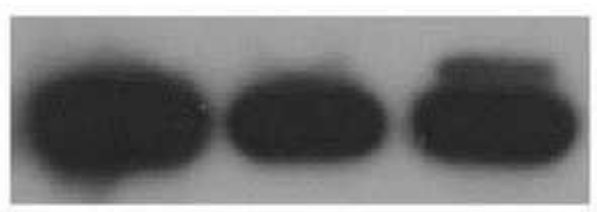

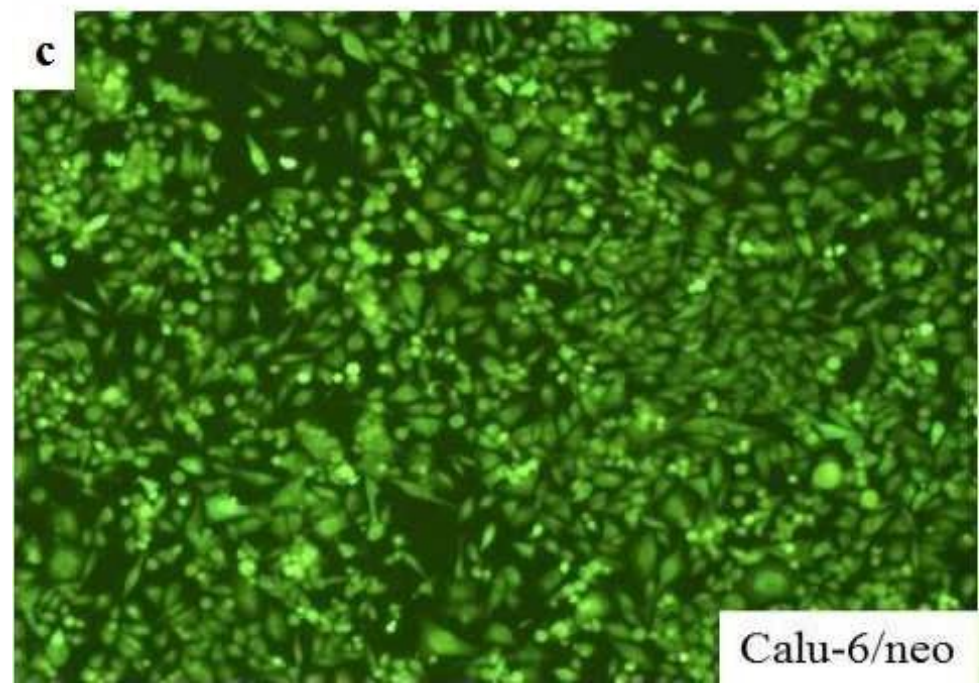

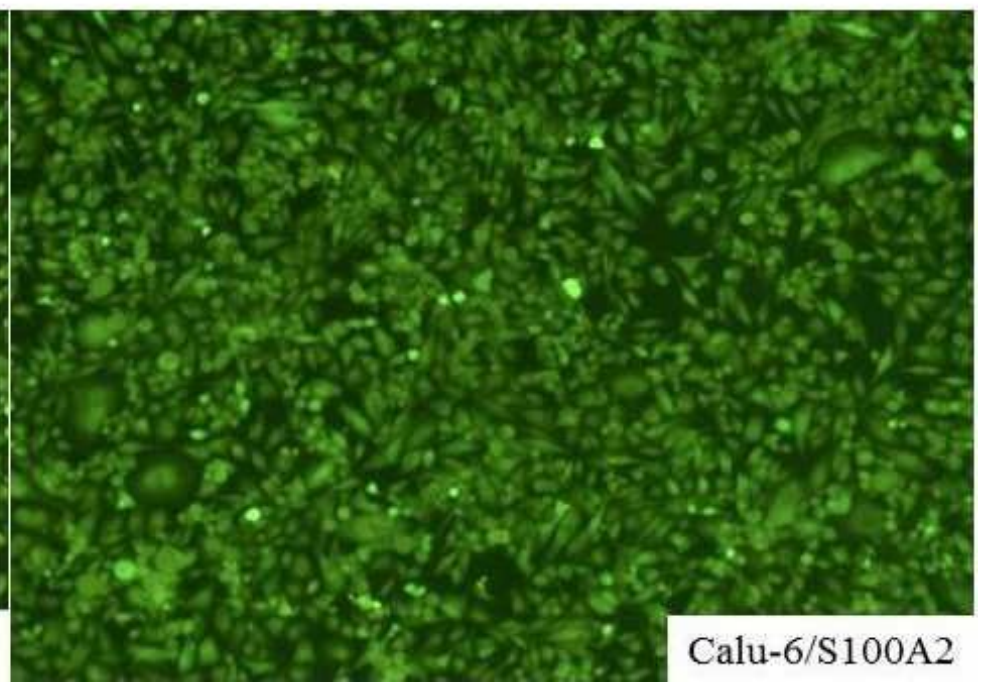

Figure 1 
S100A2's expression in three groups after transfection. a. RT-PCR showed S100A2 highly expressed in Calu-6/S100A2 cells, while had no expression in Calu- 6 and Callu-6/neo cells. b. Western-blot figure showed S100A2 expressed in Calu-6/S100A2 cells, but no expression in control groups. GAPDH expression is shown as a control in the same panel. c. Fluorogram showed Calu- 6 cells had a weak green fluorescence after being transfected with $\mathrm{S} 100 \mathrm{~A} 2$ vector.

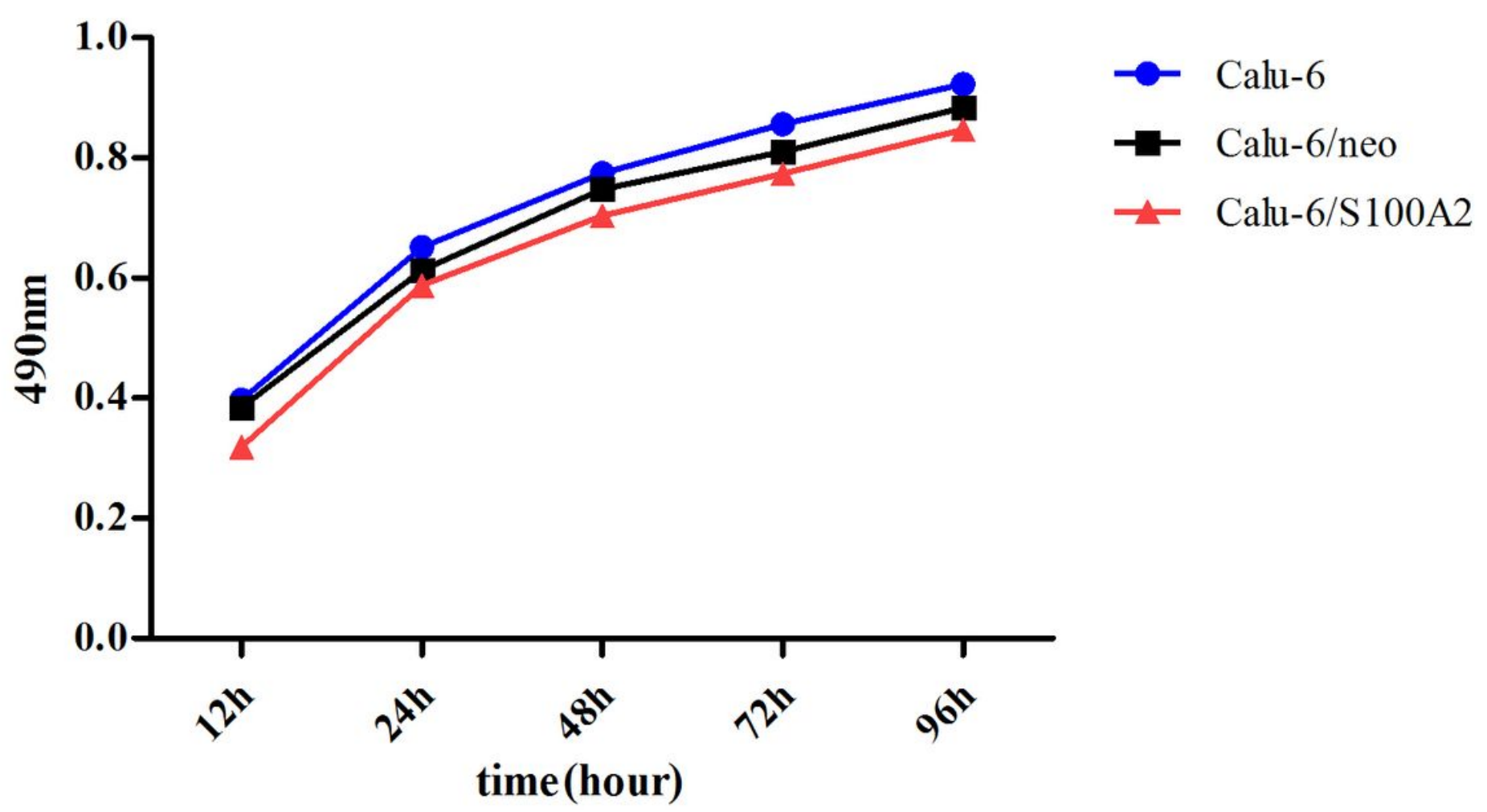

Figure 2

MTT method identified S100A2 had no effects on cell proliferation $(P>0.05)$. 

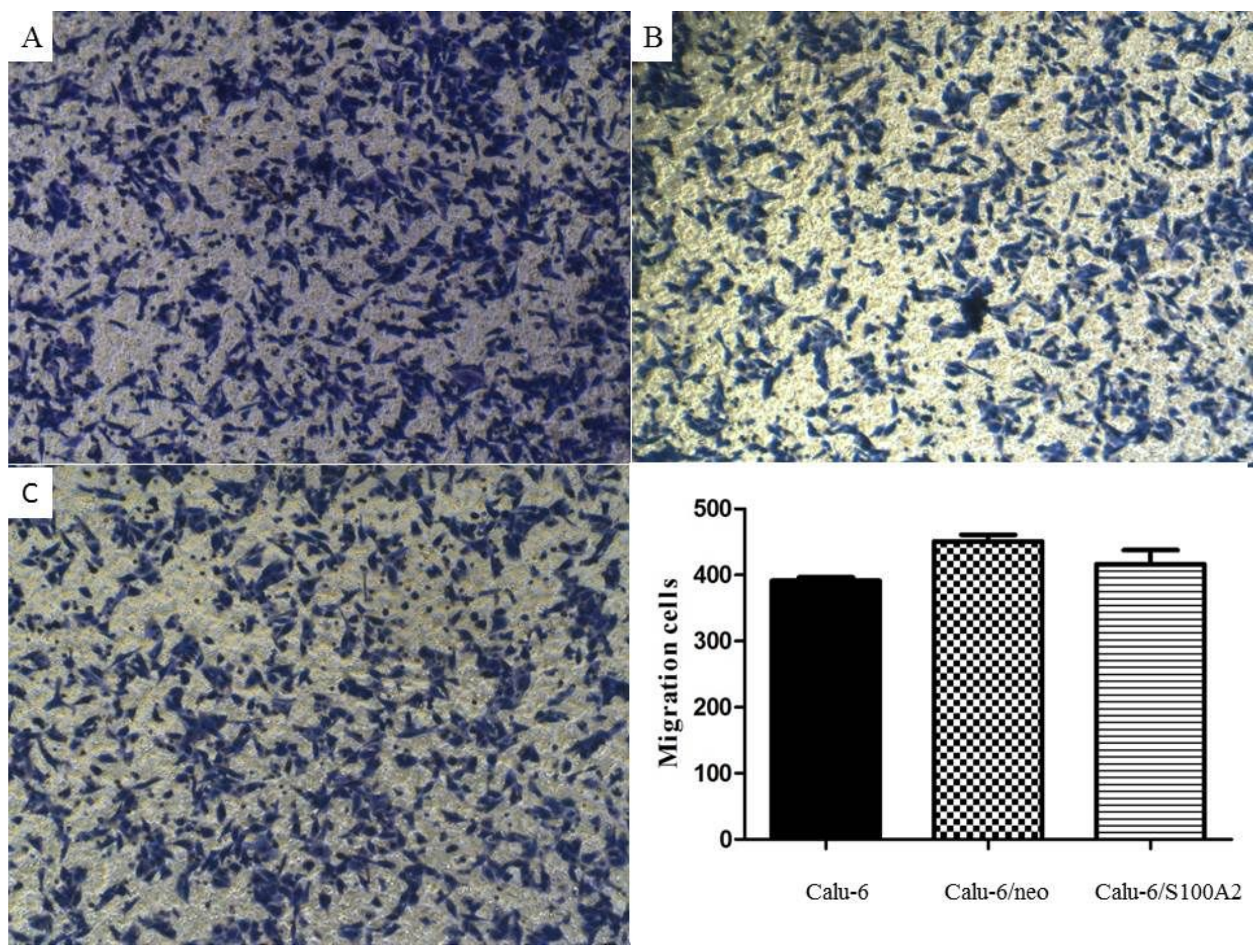

Calu-6 Calu-6/neo Calu-6/S100A2

Figure 3

S100A2 had no influence on cell migration $(P>0.05)$. 

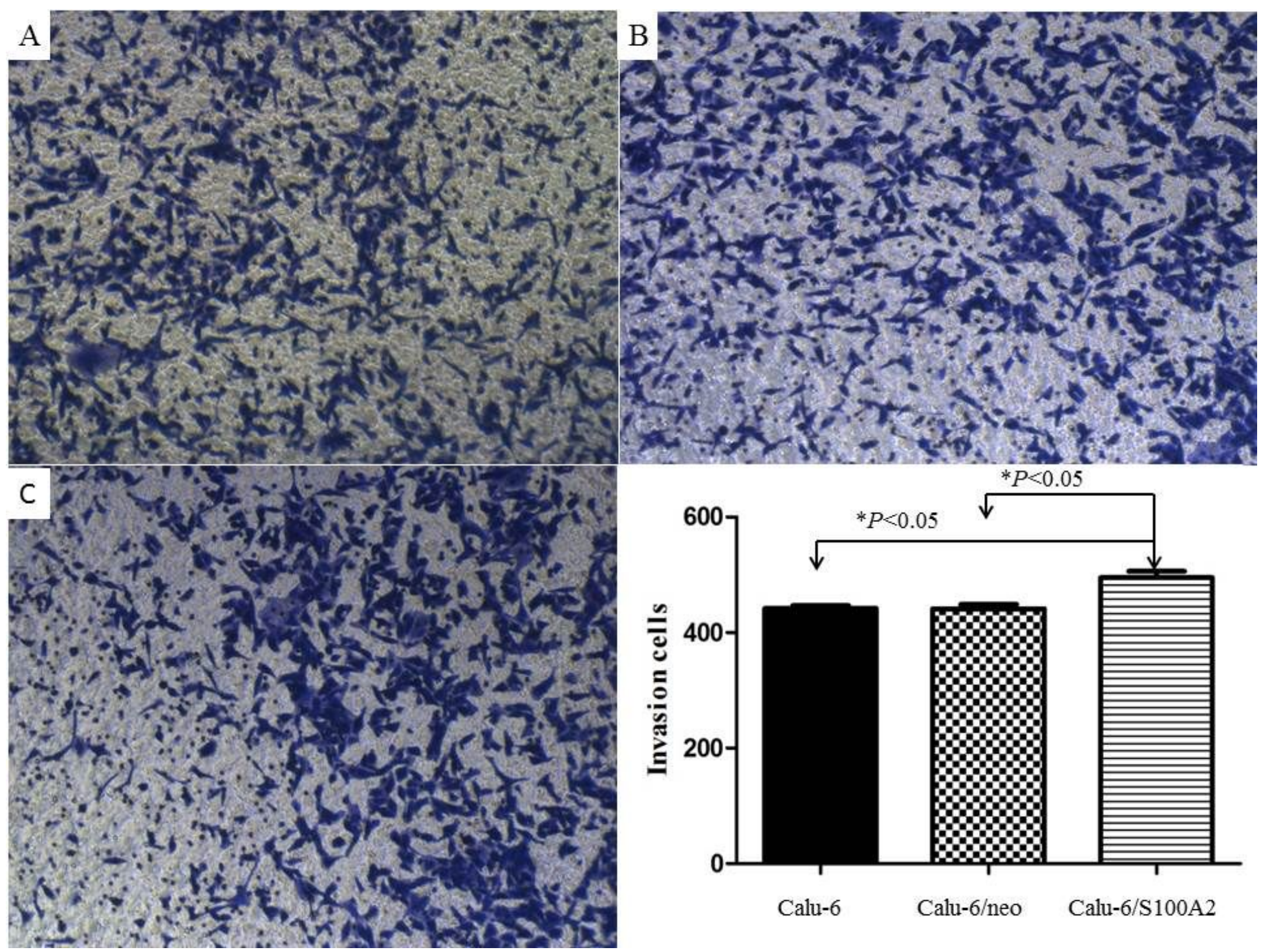

Calu-6

Calu-6/neo

Calu-6/S100A2

Figure 4

S100A2 accelerated the invasion of Calu- 6 cells $(P<0.05)$. 

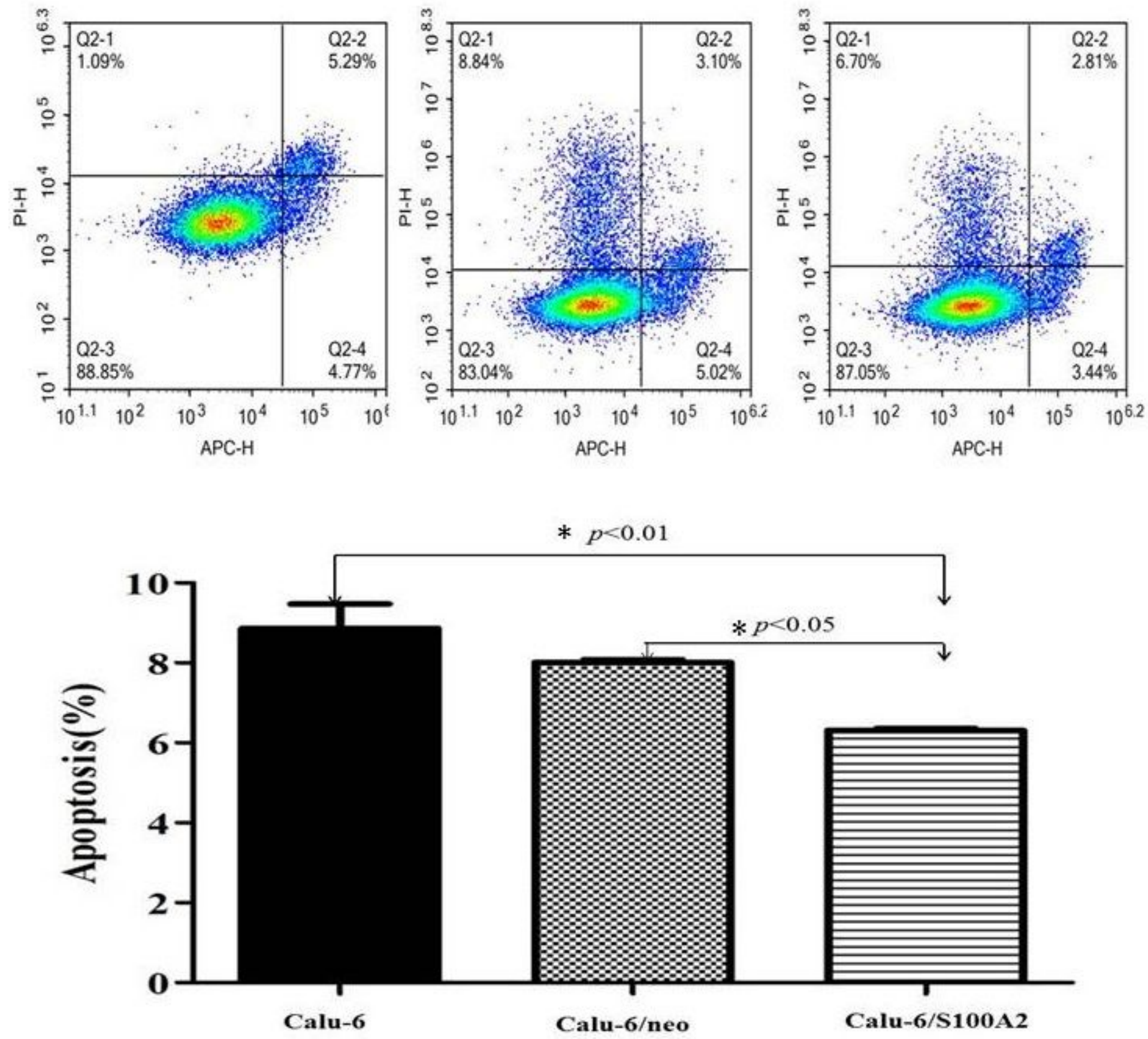

Figure 5

Flow cytometric analysis demonstrated S100A2 inhibited apoptosis of Calu- 6 cells. The percentages of apoptotic Calu-6/S100A2, Calu-6/neo and Calu-6 cells were $(6.32 \pm 0.04) \%,(8.86 \pm 0.61) \%$ and $(8.01 \pm 0.07) \%$ respectively $(P<0.05)$. 


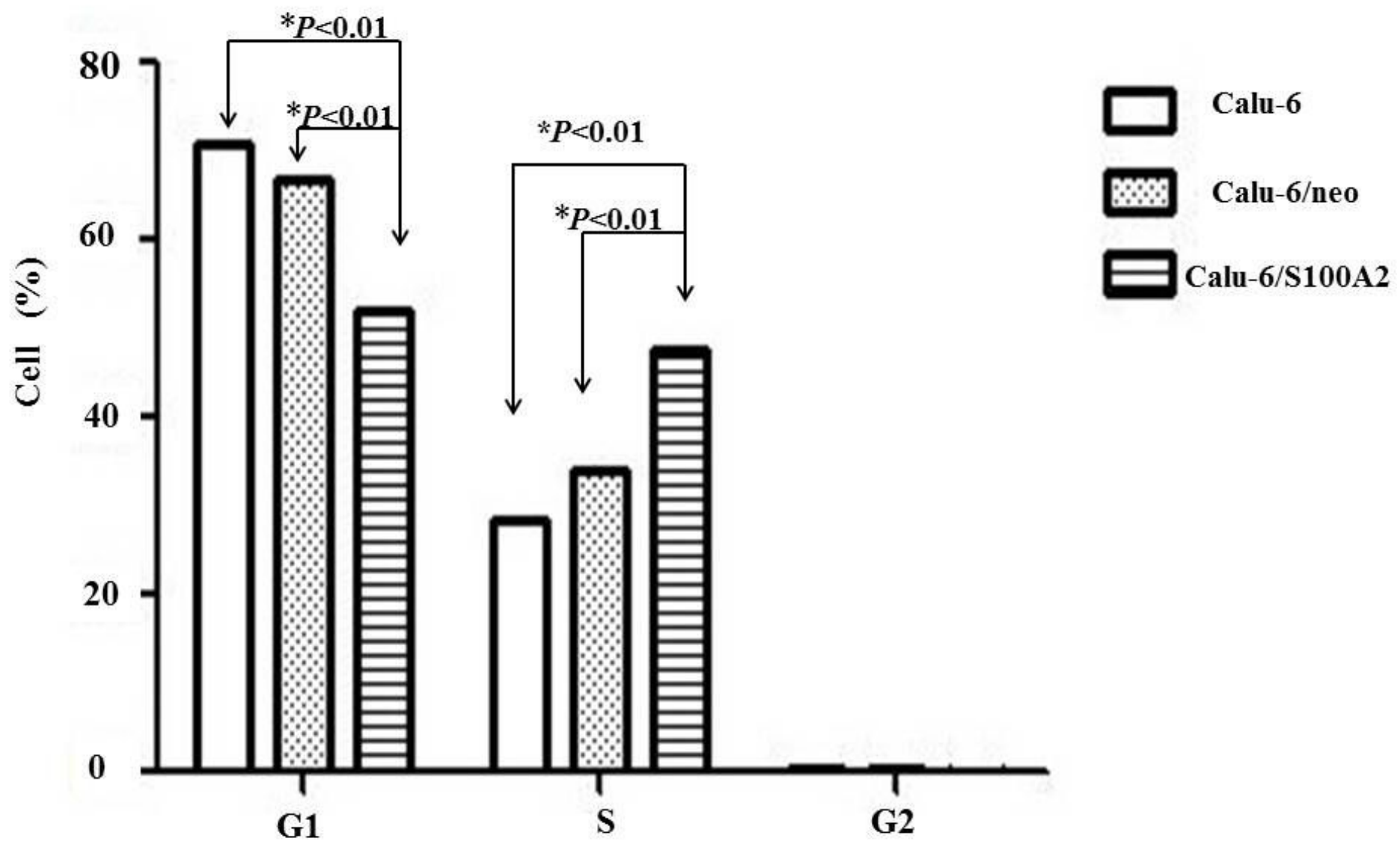

Figure 6

Flow cytometric analysis showed Calu-6/S100A2 cells had a lower percentage in $\mathrm{G} 1$ phase and higher percentage of $S$ phase $(P<0.01)$. the proportions of three groups in $\mathrm{G} 1$ phase were $(70.98 \pm 0.74) \%$ (Calu6), $(66.97 \pm 0.18) \%$ (Calu-6/neo) and (52.16 \pm 0.78$) \%$ (Calu-6/S100A2); in S phase, they were $(28.58 \pm 0.70) \%,(34.18 \pm 1.81) \%$ and $(47.69 \pm 0.84) \%$ respectively. 